\title{
Synthesis of Dioxo-Dioxane and Dioxo-Dioxepane Ethyl Oleate Derivatives as Bio-Lubricant Base Stocks
}

\author{
Tutik Dwi Wahyuningsih ${ }^{1, *}$ and Yehezkiel Steven Kurniawan ${ }^{1,2}$ \\ ${ }^{1}$ Department of Chemistry, Faculty of Mathematics and Natural Sciences, Universitas Gadjah Mada, \\ Sekip Utara, Yogyakarta 55281, Indonesia \\ ${ }^{2} \mathrm{Ma}$ Chung Research Center for Photosynthetic Pigments, Universitas Ma Chung, Malang 65151, Indonesia
}

${ }^{*}$ Corresponding author:

tel: $+62-818467863$

email: tutikdw@ugm.ac.id

Received: January 1, 2019

Accepted: March 9, 2020

DOI: $10.22146 /$ ijc. 42317

\begin{abstract}
In this study, two novel compounds, i.e., ethyl 8-(3-octyl-5,6-dioxo-1,4dioxan-2-yl)octanoate and ethyl 8-(3-octyl-5,7-dioxo-1,4-dioxepan-2-yl)octanoate were prepared from oleic acid as the starting material. Both compounds were obtained from the esterification of the ethyl 9,10-dihydroxyoctadecanoate with dicarboxylic acids in the presence of $\mathrm{p}$-toluenesulfonic acid as a catalyst. The chemical structures of the synthesized products were confirmed by FTIR, ${ }^{1} \mathrm{H}-\mathrm{NMR}$, and MS spectrometers. The bio-lubricant properties of the products, such as density, total acid number, total base number, and iodine value, were determined and the effect of the dioxane and dioxepane heterocyclic rings to their bio-lubricant properties was discussed. The esterification of ethyl 9,10dihydroxyoctadecanoate with oxalic acid gave ethyl 8-(3-octyl-5,6-dioxo-1,4-dioxan-2$y$ l)octanoate compound in $93.9 \%$ yield, while the esterification of ethyl 9,10dihydroxyoctadecanoate with malonic acid gave ethyl 8-(3-octyl-5,7-dioxo-1,4dioxepan-2-yl)octanoate compound in $89.6 \%$ yield. The density and total base number of the products were close to the standard commercial lubricant values. Meanwhile, the total acid number and the iodine value of the ethyl 8-(3-octyl-5,6-dioxo-1,4-dioxan-2$y$ l)octanoate were smaller than the standard commercial lubricant, showing that this compound is a promising bio-lubricant in a real application.
\end{abstract}

Keywords: synthesis; dioxane; dioxepane; bio-lubricant; oleic acid

\section{- INTRODUCTION}

Researches concerning bioenergy and biomaterial are increasing rapidly over the past several years [1-3]. Among them, bio-lubricant is gaining great interest because of the depleting oil-based lubricant reserves [4-5]. Bio-lubricant is an environmentally friendly product because it is biodegradable and does not contain either sulfur or harmful aromatic compounds [6-7]. Many researchers reported the availability to prepare biolubricant from vegetable oil, such as jatropha oil [8], canola oil [9], seed oil [10], and so on. However, the vegetable oil-derived bio-lubricant has several drawbacks, such as high acidic property caused by free fatty acids present and poor oxidation stability due to unsaturated fatty acids contained [11-13]. Therefore, many efforts are based on the chemical modification of vegetable oil to improve their physicochemical properties as biolubricants [14-15].

Madankar et al. modified fatty acids in canola oil through epoxidation, followed by ring-opening reaction with alcohols [9]. Furthermore, they also reported that the lubricant thermal stability increased by employing a longer carbon chain of the alkoxy ether substituent. Even though some chemical modifications of the vegetable oils were reported, ester-based lubricants were mostly developed due to the high yield obtained and the simple reaction process. Abdullah et al. prepared some polyesters of linoleic acid [16], while Salih et al. synthesized some triesters of oleic acid as bio-lubricant base stocks [17]. It was reported that polyester based lubricant performed a high viscosity index, a low pour point, a low volatility, and a high onset temperature. 
However, the polyester-based lubricant is easily hydrolyzed at high temperatures; therefore, their total acid numbers (TAN) are quite high. Sammaiah et al. reported that the TAN of the hydroxy of jatropha fatty acid alkyl ester for methyl, $n$-butyl, isopropyl, isobutyl, and 2-ethylhexyl as alkyl groups were 220.13; 224.46; 220.46; 222.52; and $195.37 \mathrm{mg} \mathrm{KOH} / \mathrm{g}$, respectively [8], which is unfavorable.

In our previous works, we reported a wide application of oleic acid to prepare bio-lubricants and biogreases [18-20]. The structure of the synthesized products in our previous work are shown in Fig. 1. The carboxylic acid functional group was modified to be an ester functional group to decrease the acidity property, and the unsaturated double bond was transformed into various heterocyclic rings to increase the oxidation stability [18]. Because of these chemical modifications, the TAN of the synthesized products were $14.53,1.71,11.00$, and $5.46 \mathrm{mg}$
$\mathrm{KOH} / \mathrm{g}$ for ketal, acetal, $\mathrm{D}[4.4]$ and $\mathrm{D}[4.5]$ compounds, respectively, which are much lower than the Sammaiah et al. reports [8]. The other physicochemical properties are satisfying enough. However, the $\mathrm{D}[4.4]$ and $\mathrm{D}[4.5]$ compounds are less stable due to the presence of the bicyclic functional group.

In the present work, the other heterocyclic rings, i.e., dioxo-dioxane and dioxo-dioxepane, were evaluated for their bio-lubricant physicochemical properties. The ethyl 8-(3-octyl-5,6-dioxo-1,4-dioxan-2-yl)octanoate (abbreviated as Cyclic-6) and ethyl 8-(3-octyl-5,7-dioxo1,4-dioxepan-2-yl)octanoate (abbreviated as Cyclic-7) were prepared through esterification between ethyl 9,10dihydroxyoctadecanoate (EtDHO) and dicarboxylic acids. The physicochemical properties of the products as bio-lubricants were examined, and the effect of the heterocyclic rings was discussed.
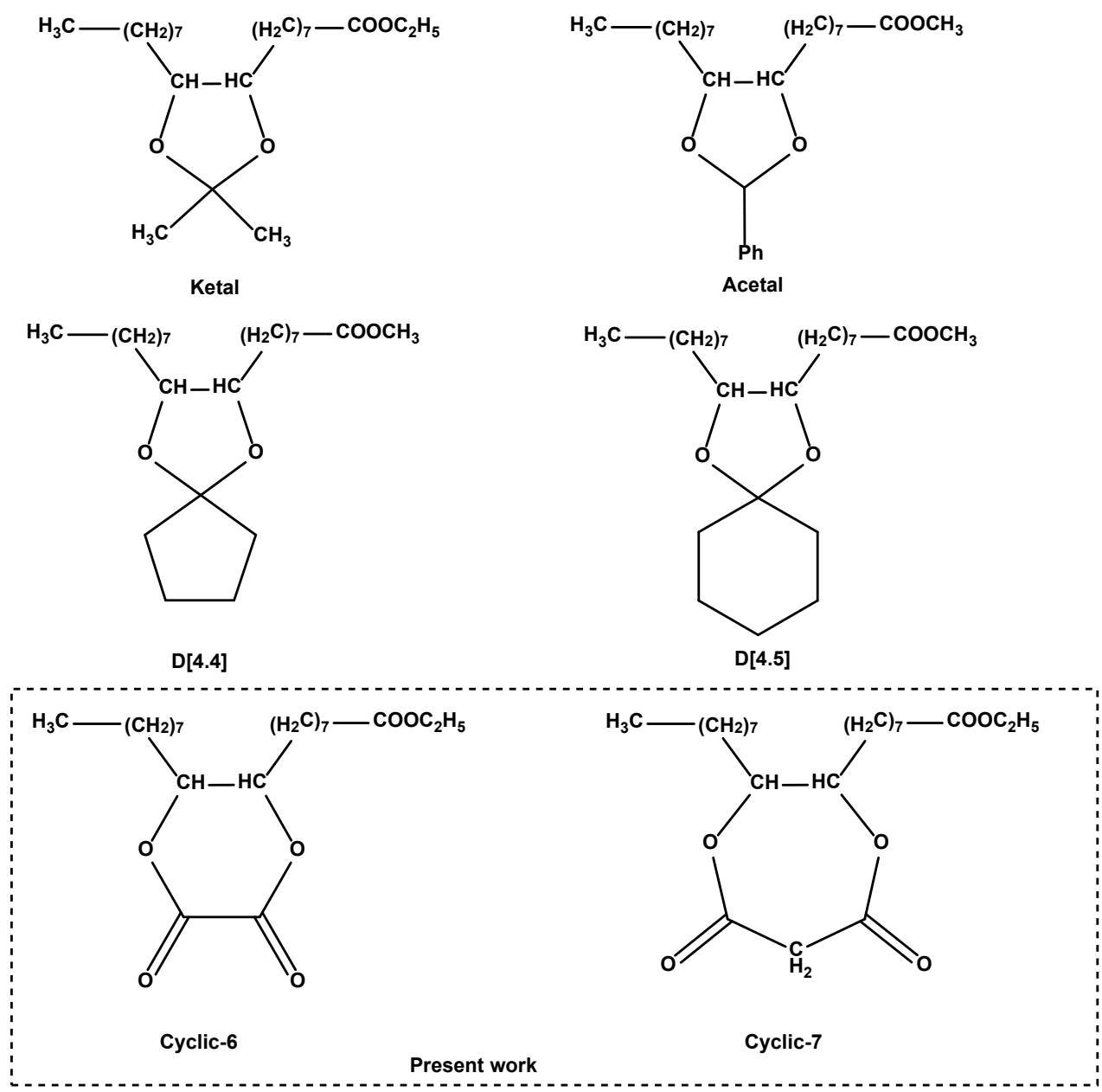

Fig 1. Prepared heterocyclic compounds derived from oleic acid in previous and present works 


\section{- EXPERIMENTAL SECTION}

\section{Materials}

Oleic acid was obtained from Sigma Aldrich, while other chemicals, such as oxalic acid dihydrate, malonic acid, $p$-toluenesulfonic acid monohydrate ( $p$ TSA), sodium bicarbonate, anhydrous sodium sulfate, acetonitrile, dichloromethane, and chloroform were in pro analysis grade and purchased from Merck. The 9,10dihydroxyoctadecanoic acid (DHOA) and ethyl 9,10dihydrooctadecanoate $(\mathrm{EtDHO})$ were prepared as previously described [18]. Commercial lubricant, Pertamina Mesran Super 20W-50, was purchased and used as a standard for the lubricants' physicochemical properties test.

\section{Instrumentation}

The Fourier Transform Infrared (FTIR) spectra of the synthesized compounds were recorded on a Shimadzu Prestige-21 FTIR spectrophotometer, while the mass spectra (MS) of the synthesized products were recorded on a Shimadzu QP 2010 S with Agilent GC Type 6890-MS Type 5973. The Proton Nuclear Magnetic resonance $\left({ }^{1} \mathrm{H}-\right.$ NMR) spectra were recorded on a JEOL-MY500 NMR Spectrometer. Density, total acid number (TAN), total base number (TBN), and iodine value (IV) were determined by titration method according to American Society for Testing and Material (ASTM) in a similar manner as previously reported [18].

\section{Procedure}

\section{Synthesis of ethyl 8-(3-octyl-5,6-dioxo-1,4-dioxan-2- yl)octanoate (Cyclic-6)}

The EtDHO (0.68 g, $2.0 \mathrm{mmol})$ was dissolved into $25 \mathrm{~mL}$ of acetonitrile. The $p$ TSA $(0.10 \mathrm{~g}, 0.5 \mathrm{mmol})$ and oxalic acid dihydrate $(1.01 \mathrm{~g}, 8.0 \mathrm{mmol})$ were added to the solution, and the mixture was refluxed for $5 \mathrm{~h}$. The solvent was evaporated, and the residue was extracted with chloroform. The organic layer was washed twice with $\mathrm{NaHCO}_{3} 10 \%(\mathrm{w} / \mathrm{v})$ and then three times with distilled water. The organic layer was dried with anhydrous $\mathrm{Na}_{2} \mathrm{SO}_{4}$, and the solvent was evaporated to obtain the desired product as a light-yellow viscous liquid in a $93.9 \%$ yield. FTIR ( $\mathrm{KBr}$ pellet, $\left.\mathrm{cm}^{-1}\right): 2924\left(\mathrm{C}-\mathrm{H} \mathrm{sp}{ }^{3}\right), 1721$, and
1697 (C=O ester), $1458\left(\mathrm{CH}_{2}\right)$, and 1265 (C-O ester). ${ }^{1} \mathrm{H}-$ NMR ( $\left.\mathrm{CDCl}_{3}, \mathrm{ppm}\right): 0.83\left(\mathrm{t}, 3 \mathrm{H},-\mathrm{CH}_{3}\right), 1.17-1.58(\mathrm{~m}$, $29 \mathrm{H},-\mathrm{CH}_{2-}$ and $\left.-\mathrm{CH}_{2} \mathrm{COOCH}_{2} \mathrm{CH}_{3}\right), 2.23(\mathrm{t}, 2 \mathrm{H}$, $\left.\mathrm{CH}_{2} \mathrm{COOCH}_{2} \mathrm{CH}_{3}\right), 3.56$ (m, 2H, -CH-O), 4.10 (q, $2 \mathrm{H}$, $\left.\mathrm{CH}_{2} \mathrm{COO} \underline{\mathrm{CH}_{2}} \mathrm{CH}_{3}\right)$. MS: $397\left(\mathrm{M}^{+}-\mathrm{H}\right), 368\left(\mathrm{M}^{+}-\mathrm{H}-\mathrm{C}_{2} \mathrm{H}_{5}\right)$, $355\left(\mathrm{M}^{+}-\mathrm{C}_{3} \mathrm{H}_{7}\right), 281,263,155,69,55,43$ (base peak).

\section{Synthesis of ethyl 8-(3-octyl-5,6-dioxo-1,4-dioxepan- 2-yl)octanoate (Cyclic-7)}

The EtDHO (0.68 g, $2.0 \mathrm{mmol})$ was dissolved into $25 \mathrm{~mL}$ of acetonitrile. The pTSA $(0.10 \mathrm{~g}, 0.5 \mathrm{mmol})$ and malonic acid $(0.832 \mathrm{~g}, 8.0 \mathrm{mmol})$ were added to the solution, and the mixture was refluxed for $5 \mathrm{~h}$. The solvent was evaporated, and the residue was extracted with dichloromethane. The organic layer was washed 3 times with $\mathrm{NaHCO}_{3} 10 \%(\mathrm{w} / \mathrm{v})$ and then 4 times with distilled water. The organic layer was dried with anhydrous $\mathrm{Na}_{2} \mathrm{SO}_{4}$, and the solvent was evaporated to obtain the desired product as a light-yellow viscous liquid in $89.6 \%$ yield. FTIR (KBr pellet, $\left.\left.\mathrm{cm}^{-1}\right): 2940(\mathrm{C}-\mathrm{H} \mathrm{sp})^{3}\right)$, 1713 , and $1680(\mathrm{C}=\mathrm{O}$ ester $), 1427\left(\mathrm{CH}_{2}\right)$, and $1250(\mathrm{C}-\mathrm{O}$ ester). ${ }^{1} \mathrm{H}-\mathrm{NMR}\left(\mathrm{CDCl}_{3}, \mathrm{ppm}\right): 0.84\left(\mathrm{t}, 3 \mathrm{H},-\mathrm{CH}_{3}\right), 1.22-$ $1.58\left(\mathrm{~m}, 29 \mathrm{H},-\mathrm{CH}_{2-}\right.$ and $\left.-\mathrm{CH}_{2} \mathrm{COOCH}_{2} \mathrm{CH}_{3}\right), 2.25(\mathrm{t}$, $2 \mathrm{H},-\mathrm{CH}_{2} \mathrm{COOCH}_{2} \mathrm{CH}_{3}$ ), 3.55 (m, 2H, - $\mathrm{CH}-\mathrm{O}$ ), 3.98 (d, $2 \mathrm{H}, \mathrm{CO}-\mathrm{CH}_{2}-\mathrm{CO}$ ), 4.09 (q, $2 \mathrm{H},-\mathrm{CH}_{2} \mathrm{COOC \textrm {CH } _ { 2 }} \mathrm{CH}_{3}$ ). MS: $410\left(\mathrm{M}^{+}-2 \mathrm{H}\right), 367\left(\mathrm{M}^{+}-2 \mathrm{H}-\mathrm{C}_{3} \mathrm{H}_{7}\right), 263,155,137,69,55$ (base peak), 43 .

\section{- RESULTS AND DISCUSSION}

\section{Synthesis of Cyclic-6 and Cyclic-7}

The synthesis scheme of Cyclic- 6 and Cyclic-7 compounds from oleic acid as the starting material is shown in Fig. 2. The first reaction is a hydroxylation by using potassium permanganate as the oxidation agent in an alkaline condition to give 9,10-dihydroxyoctadecanoic acid (DHOA) compound. Afterward, the carboxylic acid of DHOA was esterified with ethanol in the presence of montmorillonite KSF as an acid catalyst to form EtDHO compound. Finally, the desired compounds were obtained by cyclization through the esterification between the diol functional group of the EtDHO compound with a dicarboxylic acid. Cyclization of EtDHO with oxalic acid produced dioxane heterocyclic ring in the Cyclic-6 compound, while cyclization of EtDHO with malonic acid 


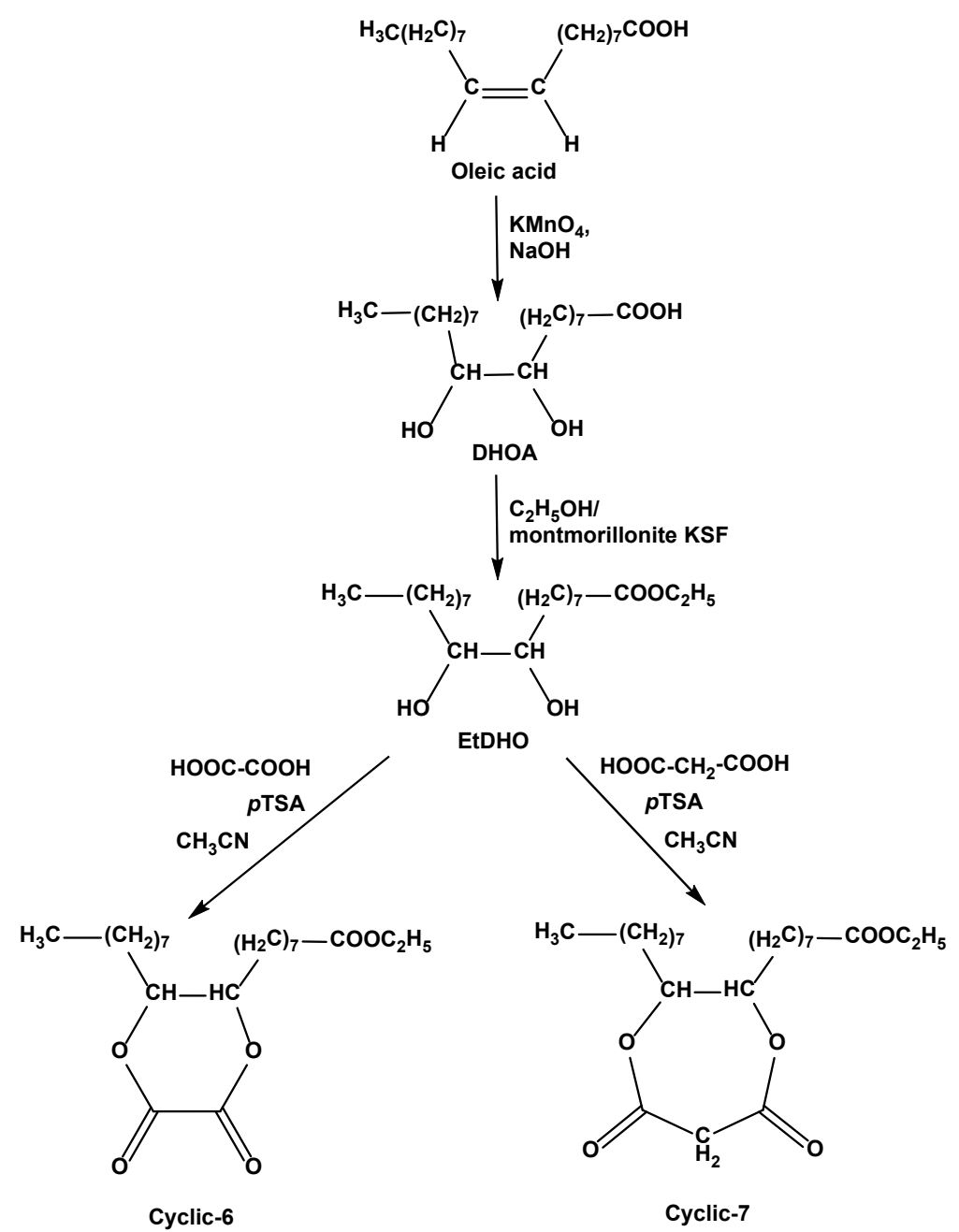

Fig 2. Synthesis scheme of Cyclic-6 and Cyclic-7 compounds from oleic acid

produced a dioxepane heterocyclic ring in the Cyclic-7 compound. The Cyclic- 6 and Cyclic-7 were obtained in high yield, i.e., 93.9 and $89.6 \%$, respectively, which is remarkable. Furthermore, both are novel compounds, which have never been reported before to the best of our knowledge.

The chemical structures of both products were confirmed by FTIR and ${ }^{1} \mathrm{H}-\mathrm{NMR}$ analysis. The FTIR spectra of Cyclic-6 and Cyclic-7 compounds are shown in Fig. 3. The absence of a broad peak around $3000-3500 \mathrm{~cm}^{-1}$ showed that the hydroxyl $(-\mathrm{OH})$ groups were completely esterified. The presence of two strong peaks at 1680$1725 \mathrm{~cm}^{-1}$ emphasized that each of the synthesized compounds has two $\mathrm{C}=\mathrm{O}$ ester groups, which are chemically nonequivalent. The absorption peak of the methylene $\left(-\mathrm{CH}_{2^{-}}\right)$functional groups showed at 1458 and
$1427 \mathrm{~cm}^{-1}$ for Cyclic-6 and Cyclic-7, respectively. Meanwhile, the absorption peak of the $\mathrm{C}-\mathrm{O}$ ester functional groups was found at 1265 and $1250 \mathrm{~cm}^{-1}$ for Cyclic-6 and Cyclic-7, respectively.

The chemical structure of the Cyclic-6 was elucidated by ${ }^{1} \mathrm{H}-\mathrm{NMR}$ spectra (data not shown). A triplet peak at $1.29 \mathrm{ppm}$ and a quartet peak at $4.10 \mathrm{ppm}$ confirmed that ethyl ester was formed. However, the dioxane heterocyclic ring could not be proven by using ${ }^{1} \mathrm{H}$-NMR spectra because there is no additional proton after the esterification with oxalic acid. The ${ }^{1} \mathrm{H}-\mathrm{NMR}$ spectrum of the Cyclic-7 product is shown in Fig. 4. The ethoxy functional group in Cyclic-7 was confirmed by the presence of triplet peak at $1.29 \mathrm{ppm}(3 \mathrm{H}$, overlapped with other peaks) and quartet peak at $4.09 \mathrm{ppm}(2 \mathrm{H})$. Furthermore, the methylene group from the malonic acid 


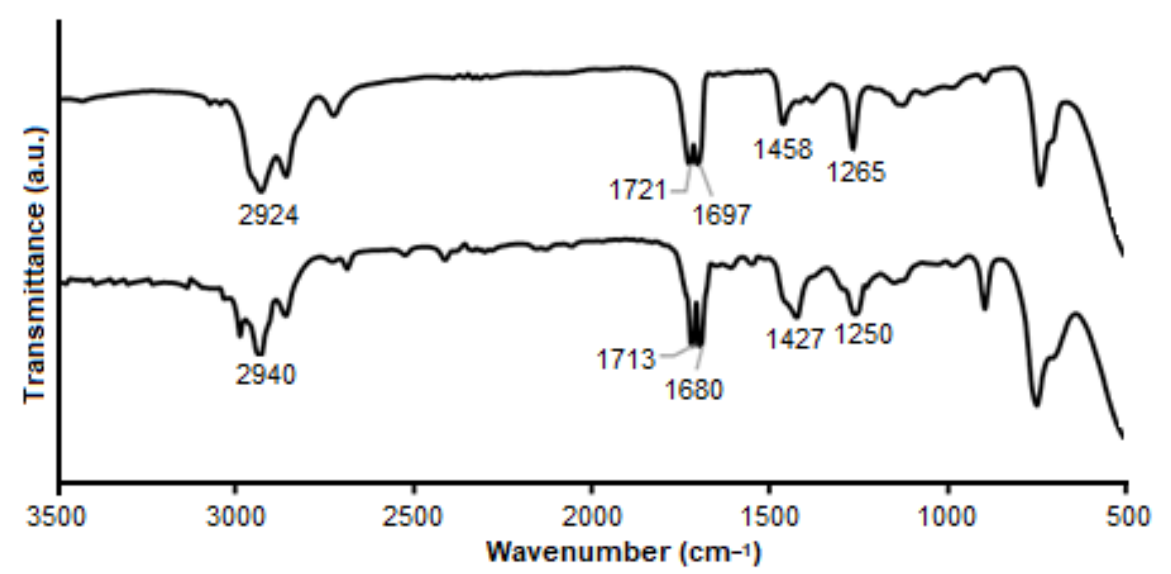

Fig 3. FTIR spectra of (a) Cyclic-6 and (b) Cyclic-7 compounds

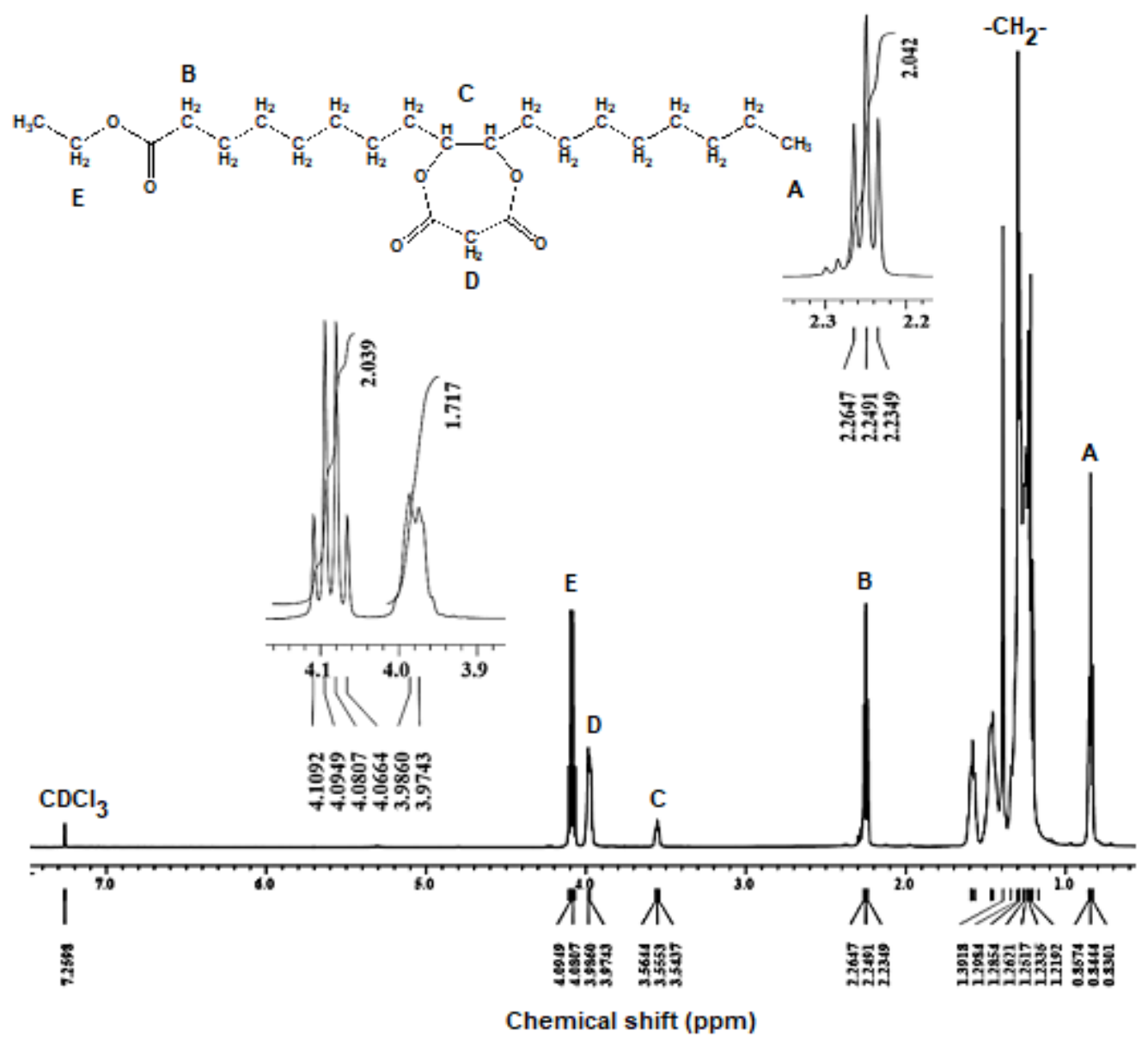

Fig 4. ${ }^{1} \mathrm{H}-\mathrm{NMR}$ spectra of Cyclic-7 compound

appeared as a doublet at $3.98 \mathrm{ppm}(2 \mathrm{H})$ due to the geminal coupling. The other protons also appeared and were assigned, as shown in Fig. 3. Both FTIR and ${ }^{1} \mathrm{H}-\mathrm{NMR}$ spectra confirmed that Cyclic-6 and Cyclic-7 compounds had been successfully prepared.
The Physicochemical Properties of Cyclic- 6 and Cyclic-7 as Bio-lubricants

The physicochemical properties of Cyclic- 6 and Cyclic-7 are shown in Table 1. The density of Cyclic- 6 and Cyclic-7 are both higher than ketal, acetal, D[4.4], 
Table 1. Bio-lubricant physicochemical properties of the products

\begin{tabular}{llccccc}
\hline \multirow{2}{*}{ No } & \multicolumn{1}{c}{ Compounds } & \multicolumn{5}{c}{ Physicochemical properties } \\
\cline { 3 - 6 } & & $\begin{array}{c}\text { Density } \\
(\mathrm{g} / \mathrm{mL})\end{array}$ & $\begin{array}{c}\text { TAN } \\
(\mathrm{mg} \mathrm{KOH} / \mathrm{g})\end{array}$ & $\begin{array}{c}\text { TBN } \\
(\mathrm{mg} \mathrm{KOH} / \mathrm{g})\end{array}$ & $\begin{array}{c}\text { IV } \\
\left(\mathrm{mg} \mathrm{I}_{2} / \mathrm{g}\right)\end{array}$ & Ref. \\
\hline 1 & Ketal & 0.824 & 14.53 & 48.95 & 0.76 & {$[19]$} \\
2 & Acetal & - & 1.71 & 14.12 & 0.25 & {$[20]$} \\
3 & D[4.4] & 0.916 & 11.00 & 24.24 & 21.28 & {$[18]$} \\
4 & D[4.5] & 0.913 & 5.46 & 14.04 & 17.73 & {$[18]$} \\
5 & Cyclic-6 & 1.045 & 1.37 & 3.53 & 0.72 & This work \\
6 & Cyclic-7 & 0.939 & 2.89 & 6.61 & 0.69 & This work \\
7 & Oleic acid & 0.985 & 196.80 & 0.54 & 89.90 & This work \\
8 & Commercial lubricant & 0.893 & 85.37 & 5.36 & 31.73 & This work \\
\hline
\end{tabular}

and $\mathrm{D}[4.5]$ compounds. The higher density of Cyclic- 6 and Cyclic-7 are probably caused by stronger intermolecular hydrophobic interaction. The density of Cyclic- 6 was the highest due to the highest stability of the dioxane ring amongst all rings. It is well known that a sixmembered ring is more stable and well-arranged than the seven-membered ring; therefore, it is in agreement with the measured density property [18].

The TAN value represents a possible corrosion level to the engine caused by using the lubricant. Compared to the hydroxy fatty acid alkyl ester of jatropha [8], the TAN values of the synthesized products decrease significantly by the formation of dioxane and dioxepane heterocyclic rings. It means that a cyclic ester functional group is preferable than polyester substituents. From Table 1, it is shown that the TAN values of Cyclic- 6 and Cyclic-7 are lower than others, demonstrating that both compounds are preferable due to low corrosion level to the engine. The low TAN of Cyclic- 6 and Cyclic- 7 were caused by their stability against the acid hydrolysis process. The TAN value of Cyclic- 6 is the lowest because of a stable sixmember heterocyclic ring. Similar to the TAN results, the TBN value of the Cyclic- 6 is the lowest, demonstrating that the Cyclic- 6 compound is very stable to acid hydrolysis as well as the alkaline hydrolysis process.

The IV value represents the stability of the compound towards oxidation. Unsaturated fatty acid, such as oleic acid, has a high IV value due to the presence of the $\mathrm{C}=\mathrm{C}$ double bond. Through chemical modifications of oleic acid, the IV significantly decreased, as shown in Table 1. The IV values of Cyclic- 6 and Cyclic-7 compounds are less than $1.00 \mathrm{mg} \mathrm{I}_{2} / \mathrm{g}$, showing that they are stable against the oxidation process. Compared to the commercial lubricant, Cyclic- 6 and Cyclic 7 are better because their TAN and IV values are lower. Therefore, Cyclic- 6 and Cyclic-7 are promising bio-lubricant candidates because of the shown excellent lubricant properties.

\section{- CONCLUSION}

The Cyclic-6 and Cyclic-7 compounds were successfully synthesized from the esterification between EtDHO and oxalic acid and malonic acid, respectively. From the results, Cyclic-6 bio-lubricant gave lower TAN, demonstrating that Cyclic- 6 is more stable than Cyclic7 for acid hydrolysis. The density and TBN of the Cyclic6 bio-lubricant are similar to the commercial lubricant. These findings are useful for the chemical design of fatty acids to improve the physicochemical properties of the bio-lubricant derived from vegetable oils.

\section{- ACKNOWLEDGEMENTS}

Financial support from The Ministry of Research, Technology, and Higher Education of the Republic of Indonesia is highly appreciated.

\section{- REFERENCES}

[1] Zhu, Y., Romain, C., and Williams, C.K., 2016, Sustainable polymers from renewable resources, Nature, 540, 354-362.

[2] Imawan, A.C., Kurniawan, Y.S., Lukman, M.F., Jumina, Triyono, and Siswanta, D., 2018, Synthesis and kinetic study of the urea controlled release composite material: Sodium lignosulfonate from 
isolation of wood sawdust-sodium alginate-tapioca, Indones. J. Chem., 18 (1), 108-115.

[3] Wahyuningsih, T.D., Kurniawan, Y.S., Amalia, S., Wardhani, T.A.K., and Muriningsih, C.E.S., 2019, Diethanolamide derivatives as potential enhanced oil recovery from Indonesian castor oil and used frying oil: Isolation, synthesis and evaluation as nonionic biosurfactants, Rasayan J. Chem., 12 (2), 741-748.

[4] Zhou, Y., and Qu, J., 2017, Ionic liquids as lubricant additives: A review, ACS Appl. Mater. Interfaces, 9 (4), 3209-3222.

[5] Owuna, F.J., Dabai, M.U., Sokoto, M.A., Dangoggo, S.M., Bagudo, B.U., Birnin-Yauri, U.A., Hassan, L.G., Sada, I., Abubakar, A.L., and Jibrin, M.S., 2019, Chemical modification of vegetable oils for the production of biolubricants using trimethylolpropane: A review, Egypt. J. Pet., In Press, Corrected Proof.

[6] Chan, C.H., Tang, S.W., Mohd, N.K., Lim, W.H., Yeong, S.K., and Idris, Z., 2018, Tribological behavior of biolubricant base stocks and additives, Renewable Sustainable Energy Rev., 93, 145-157.

[7] Heikal, E.K., Elmelawy, M.S., Khalil, S.A., and Elbasuny, N.M., 2017, Manufacturing of environment friendly biolubricants from vegetable oils, Egypt. J. Pet., 26 (1), 53-59.

[8] Sammaiah, A., Padmaja, K.V., and Prasad, R.B.N., 2014, Synthesis and evaluation of novel acyl derivates from Jatropha oil as potential lubricant base stocks, $J$. Agric. Food Chem., 62 (20), 4652-4660.

[9] Madankar, C.S., Dalai, A.K., and Naik, S.N., 2013, Green synthesis of biolubricant base stock from Canola oil, Ind. Crops Prod., 44, 139-144.

[10] Sonnenschein, M.F., Greaves, M.R., Bell, B.M., and Wendt, B.L., 2012, Design, polymerization, and properties of high-performance seed-oil-derived lubricants, Ind. Eng. Chem. Res., 51 (25), 8386-8393.

[11] Soni, S., and Agarwal, M., 2014, Lubricants from renewable energy sources - A review, Green Chem.
Lett. Rev., 7 (4), 359-382.

[12] Panchal, T.M., Patel, A., Chauhan, D.D., Thomas, M., and Patel, J.V., 2017, A methodological review on bio-lubricants from vegetable oil based resources, Renewable Sustainable Energy Rev., 70, 65-70.

[13] Reeves, C.J., Siddaiah, A., and Menezes, P.L., 2017, A review on the science and technology of natural and synthetic biolubricants, J. Bio. Tribo. Corros., 3, 11.

[14] McNutt, J., and He, Q., 2016, Development of biolubricants from vegetable oils via chemical modification, J. Ind. Eng. Chem., 36, 1-12.

[15] Hossain, M.A., Iqbal, M.A.M., Julkapli, N.M., Kong, P.S., Ching, J.J., and Lee, H.V., 2018, Development of catalyst complexes for upgrading biomass into ester-based biolubricants for automotive applications: A review, $R S C A d v$. , 8, 5559-5577.

[16] Abdullah, B.M., Zubairi, S.I., Huri, H.Z., Hairunisa, N., Yousif, E., and Basu, R.C., 2016, Polyester based on linoleic acid for biolubricant basestocks: Lowtemperature, tribological and rheological properties, PLoS ONE, 11 (3), e0151603.

[17] Salih, N., Salimon, J., and Yousif, E., 2011, The physicochemical and tribological properties of Oleic acid based triester biolubricants, Ind. Crops Prod., 34 (1), 1089-1096.

[18] Kurniawan, Y.S., Ramanda, Y., Thomas, K., Hendra, and Wahyuningsih, T.D., 2017, Synthesis of 1,4-dioxaspiro[4.4] and 1,4-dioxaspiro[4.5] novel compounds from oleic acid as potential biolubricant, Indones. J. Chem., 17 (2), 301-308.

[19] Kurniawan, Y.S., Anwar, M., and Wahyuningsih, T.D., 2017, New lubricant from used cooking oil: Cyclic ketal of ethyl 9,10-dihidroxyoctadecanoate, Mater. Sci. Forum, 901, 135-141.

[20] Wahyuningsih, T.D., and Kurniawan, Y.S., 2017, Green synthesis of some novel dioxolane compounds from Indonesian essential oils as potential biogreases, AIP Conf. Proc., 1823 (1), 020081. 